\title{
State of the Art in Some Important Fields of Shape Memory Alloys
}

G. Guénin

GEMPPM, Bât. 502, INSA, 6962l Villeurbanne cedex, France

\begin{abstract}
Some new results of literature concerning two important fields of shape memory alloys are analyzed and commented: The origin of the shape memory in Fe-based alloys and the origin of the Two way memory effect in $\beta$ phase alloys.
\end{abstract}

Fe-based alloys

Fe-based alloys are able to exhibit Shape Memory Effect (SME) through different kinds of martensitic transformations [1] : f.c.c. to b.c.c. or b.c.t. like in ordered FesPt or ausaged Fe-Ni-Co-Ti; f.c.c. to f.c.t. like in Fe-Pd; f.c.c. to h.c.p. like in Fe-Mn-Si. The two former kinds involve prohibitive cost alloys (Fe-Pt, Fe-Pd) or poor shape memory properies obtained with very particular treatments (Fe-NiCo-Ti). The later kind has received more attention these last years due to relatively good shape memory properties associated to a low alloy cost in addition with the possibility of resistance to corrosion with alloying elements. This development will be focussed on the new results concerning these alloys. The FeMn-Si shape memory alloy has been discovered by Sato et al in single crystals [2,3]. A little later it was observed in polycrystals $[4,5]$. The nearly perfect SME observed in these alloys appears to be very different from the one of "classical" SM alloys : it involves a distinct crystallography and the transformation is non thermoelastic in nature. The transformation as well as the SM properties are very sensitive to the para-antiferromagnetic transition of the austenite which ocurs at $T_{N}$ (Neel temperature). Moreover, in contrast with "classical" SM alloys, the martensitic transformation is also very sensitive to the microstructure (thermomechanical history) of the alloy. It is not easy to separate the respective importance of these two aspects. Some recent results have clarified this problem.

Yang et al $[6,7,8]$ have precised the influence of the $T_{N}$ position in relation to the $M_{S}$ temperature throug three alloys $\mathrm{Fe}-\mathrm{Mn}-\mathrm{Si}(\mathrm{Cr}-\mathrm{Ni}-\mathrm{Co}-\mathrm{Al})$ :

$A$ with $M_{S}=300 \mathrm{~K}, A_{S}=360 \mathrm{~K}$ and $T_{N}=230 \mathrm{~K}\left(T_{N}\right.$ just below $\left.M_{S}\right)$

$B$ with $M_{S}<150 \mathrm{~K}, A_{S}<270 K$ and $T_{N}=260 K\left(T_{N}\right.$ above $\left.M_{S}\right)$

$C$ with $M_{S}=340 \mathrm{~K}, A_{s}=375 K$ and $T_{N}=90 \mathrm{~K}\left(T_{N}\right.$ well below $\left.M_{S}\right)$

All the samples are solution treated at $1300 \mathrm{~K}$ for 1 hour and water quenched. They are submitted to bending strains at room temperature $(300 \mathrm{~K})$ and at liquid nitrogen temperature $(77 \mathrm{~K})$. It is shown that the strain can be divided into three parts : suppressed

- a "superelastic strain" (SE) including pure elastic strain and which occurs when the stress is

- a "shape memory effect" (SME) which is recovered by heating at about $750 \mathrm{~K}$

- a "retained strain" (RS) which is the remaining strain

An original triangle representation is used to show these values as a function of strain amplitude. The figure 1 shows the behaviour for the three kinds of alloys :

The A alloy (high $M_{S}$ and $T_{N}$ just below) and $B$ alloy (high $T_{N}$ low $M_{S}$ ) exhibit a very large dependance on the temperature at which the strain is performed, whereas the $C$ alloy (high $\mathbf{M}_{\mathbf{S}}$ low $\mathrm{T}_{\mathrm{N}}$ ) shows little difference between the two temperatures. 
For alloy A bent at room temperature SE and SME are of the same order of magnitude (1-2\%) whereas for prestrain at liquid nitrogen temperature the SME is largely increased and the SE decreased. The same is observed for alloy B but the SME is reduced and SE increased.
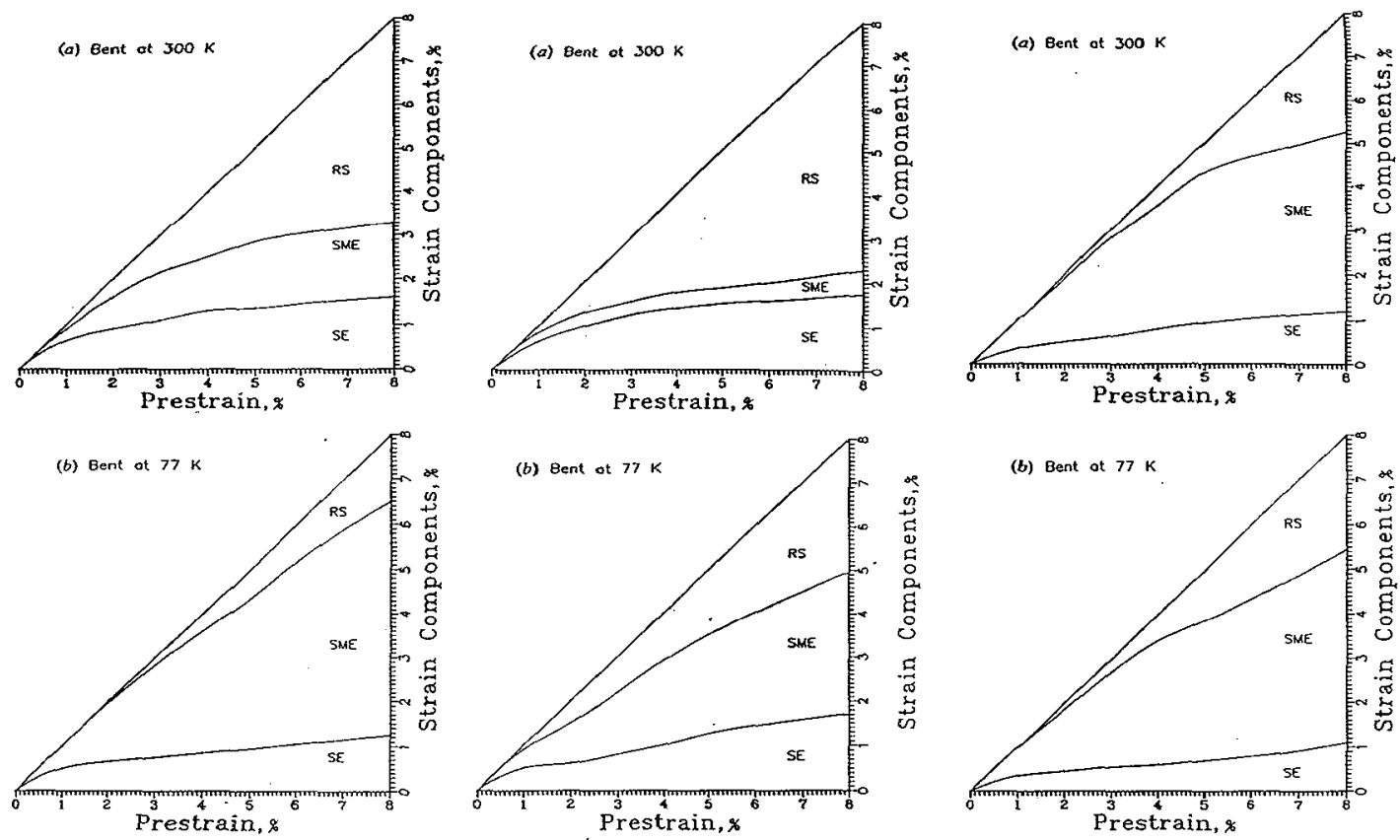

alloy $\mathrm{A}$

alloy $\mathrm{B}$

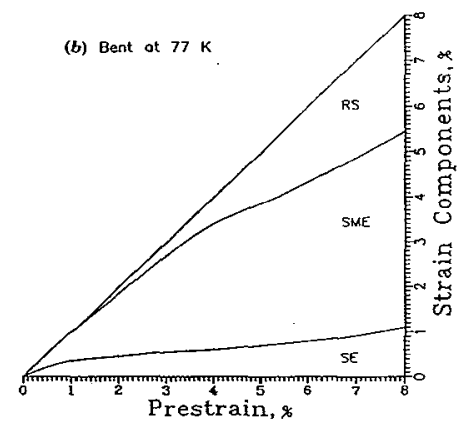

alloy $\mathrm{C}$

figure 1-Constituent diagram showing the three components of strain as a function of prestrain :

Superelasticity (SE), Shape memory effect (SME) and retained strain (RS). After Yang et al [6].

This behaviour is clarified with complementary experiments, especially electrical resistance shown in figure 2. The amount of thermal martensite obtained at $77 \mathrm{~K}$ in the A alloy is very small (curve $2 \mathrm{~A}$ ); the resistance minimum is due to the Neel transition. The room temperature bending induces a small increase of the resistance (stress induced martensite) which slowly reverts by heating (curve 3A). The 77K bending induces a larger increase which reverts more abruptly than in the previous case at about $370 \mathrm{~K}$ (curve $4 \mathrm{~A}$ )

The amount of thermal martensite obtained at $77 \mathrm{~K}$ in the alloy $\mathrm{C}$ is large (curve $2 \mathrm{C}$ ) and reverts at about $380 \mathrm{~K}$ on heating. The room temperature bending induces a resistance increase like in the previous case which reverts by heating in a larger temperature range than for thermal martensite (curve 3C). When the bending occurs at $77 \mathrm{~K}$ about the same increase of the resistance is seen which is superimposed to the one of the thermal martensite (curve $4 \mathrm{C}$ ), the reversion seems to be a superposition of curves $2 \mathrm{C}$ and $3 \mathrm{bC}$ )

The main conclusions of this study are:

-When the $\mathbf{T}_{N}$ temperature is above $\mathbf{M}_{\mathbf{S}}$ (alloy B) or slightly below (alloy A) it strongly inhibits the thermal martensitic transformation by stabilization of the $\gamma$ phase, this have also been confirmed by electron microscopy observations [8]

-The preexisting thermal martensite does not decrease the SME : for alloys A and B the SME is increased when the alloy is strained at low temperature below $\mathbf{M}_{\mathbf{S}}$, however little thermal martensite is present in this case. For alloy $\mathrm{C}$ no difference is observed for SME after deformation at $77 \mathrm{~K}$ where about $40 \%$ thermal martensite is present or at room temperature with little thermal martensite.

-The $\varepsilon$ martensite can be strain induced on the influence of antiferromagnetism.

-Some significant superelastic effect is observed which can be increased by thermomechanical treatment . This is the first observation for this kind of non thermoelastic alloy.

To separate the influence of $\mathbf{T}_{\mathbf{N}}$ from the one of the previous thermomechanical treatments it is interresting to choose an alloy of the $\mathrm{C}$ type where the influence of antiferromagnetism can be neglected. Some recent results have been obtained for this kind of alloy by Federzoni [9]. In this work, a detailled study in this way is done on a Fe-Mn-Cr-Ni-Si alloy with $\mathrm{M}_{\mathrm{s}}$ around room temperature, $\mathrm{A}_{\mathrm{s}}$ around $140^{\circ} \mathrm{C}$ and $\mathrm{T}_{\mathrm{N}}$ around $-180^{\circ} \mathrm{C}$. The studv has been made easier by the use of ThermoElectric Power measurements 

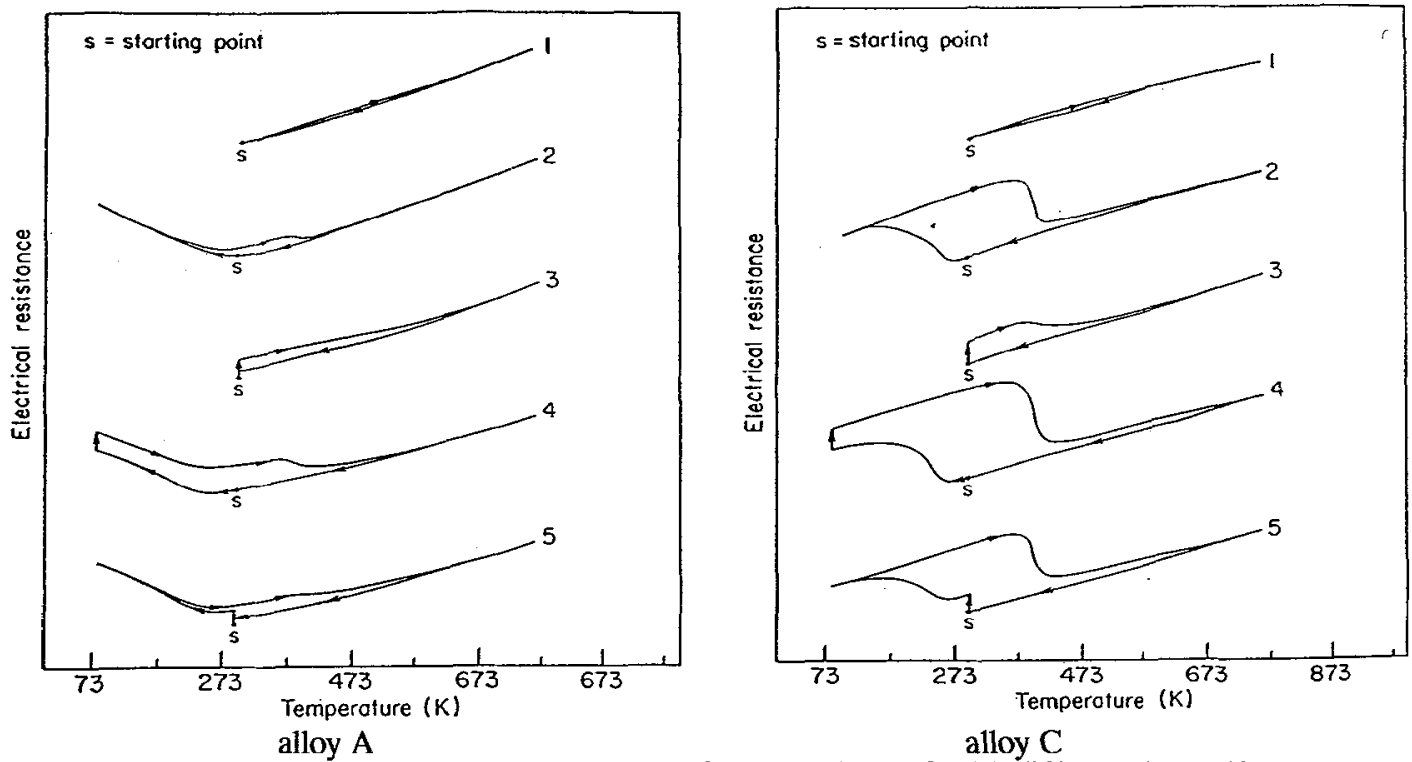

figure 2-Electrical resistance curves for alloys $\mathrm{A}$ and $\mathrm{C}$ with different thermal/ mechanical routes : (1) RT-750K-RT, (2) RT-77K-750K-RT, (3) Bent at RT-750K-RT, (4) RT-Bent at 77K-750K-RT, (5) Bent at RT-77K-750K-RT. After Yang et al [7]

(TEP) which are very convenient to detect the fraction of $\varepsilon$ martensite in a sample : the figure 3 displays the relation between the TEP and the $\varepsilon$ martensite fraction measured by $\mathrm{X}$ ray diffraction analysis [10]. For a sample initially obtained from a cold rolled sheet, the reversion of the strain induced $\varepsilon$ martensite (and $\alpha^{\prime}$ martensite) occurs between 400 and $550^{\circ} \mathrm{C}$. For anealings above $600^{\circ} \mathrm{C}$ the alloy is fully austenitic at room temperature and subsequent cooling at liquid nitrogen can be done to induce the $\varepsilon$ martensite which fraction can be measured at room temperature by TEP since the $\mathrm{A}_{\mathbf{s}}$ temperature is well above. The results can be seen on figure $4:$ a large amount of thermal martensite is measured for annealing temperatures below $800^{\circ} \mathrm{C}$ whereas very little fraction is observed for $800^{\circ} \mathrm{C}-900^{\circ} \mathrm{C}$ annealings; a slight increase is present for higher temperatures. The recrystallization of the alloy occurs around $800^{\circ} \mathrm{C}$, therefore the annealings between $600^{\circ} \mathrm{C}$ and $800^{\circ} \mathrm{C}$ correspond to restaured states. This last state seems to be favourable to the thermal martensite. This is confirmed by anealing experiments after several deformation rates on well annealed samples (figure 5) : for a $750^{\circ} \mathrm{C} 45 \mathrm{~min}$. annealing, the fraction of thermal $\varepsilon$ martensite obtained by liquid nitrogen cooling first increases with the deformation rate, attains a maximum for approximately $7 \%$ strain and finally decreases for larger deformations. This is coherent with the fact that a restaured state is favourable to the $\varepsilon$ generation : It is well known that the annealing after cold working can lead to two different states; the restaured state for small deformations (here 7\%) and the recrystallized state for high deformation. A remarquably high fraction of thermal martensite $(65 \%)$ is obtained by this way. The thermal cycling between temperatures below $\mathbf{M}_{\mathbf{s}}$ and above $\mathrm{A}_{\mathbf{f}}$ is also able to increase the fraction of thermal martensite $[9,11]$ but the maximum attained is always smaller $(30-40 \%)$.

All these results are coherent with the fact that the dislocations play an important role in the $\varepsilon$ martensite nucleation and growth : They favour the nucleation and the bebinning of the growth, however they probably slow down the growth when their density is two high (annealing at $600^{\circ} \mathrm{C}$ in figure 4).

The fact that the thermal martensite is very sensitive to the microstructure does not necessarily imply that the strain $\varepsilon$ martensite is identically influenced. To illustrate this, two samples have been treated to potentially have very different thermal $\varepsilon$ martensite fraction [9]:

sample I is restaured $10 \mathrm{~min}$. after $7 \%$ deformation which can produce $65 \%$ thermal martensite. sample II is well annealed and does not produce any thermal martensite.

These two samples deformed at room temperature give exactly the same strain $\varepsilon$ martensite fraction as shown on figure 6. It can therefore be concluded that the microstructure has little effect on the production of 


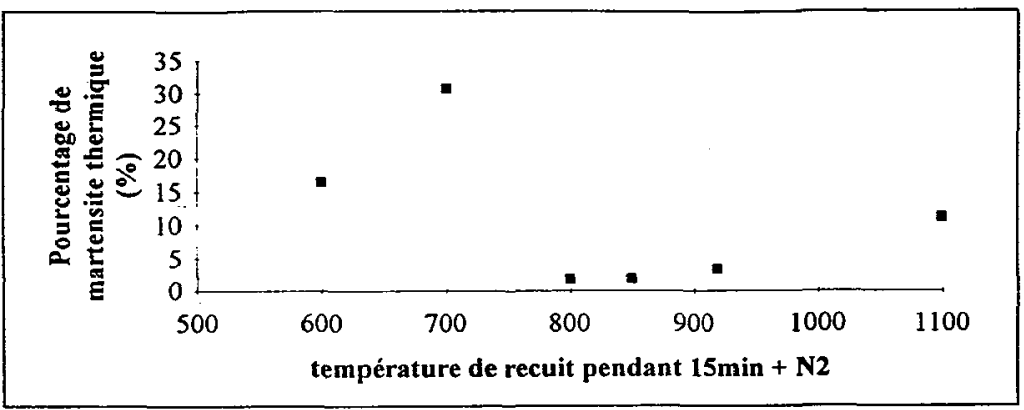

figure 4- $\varepsilon$ martensite fraction obtained after different annealing temperatures and liquid nitrogen cooling. After Federzoni [9]

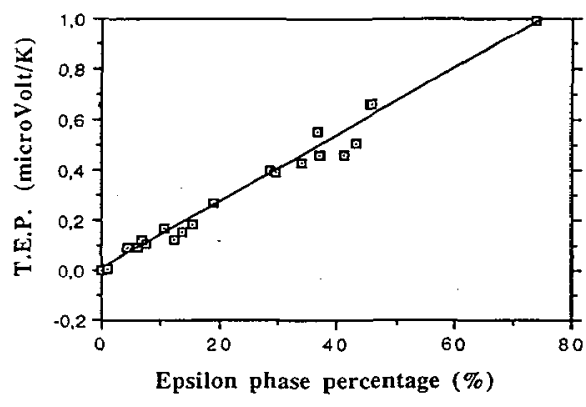

figure 3- Changes in TEP as a function of $\varepsilon$ martensite fraction. After Federzoni et al [10]

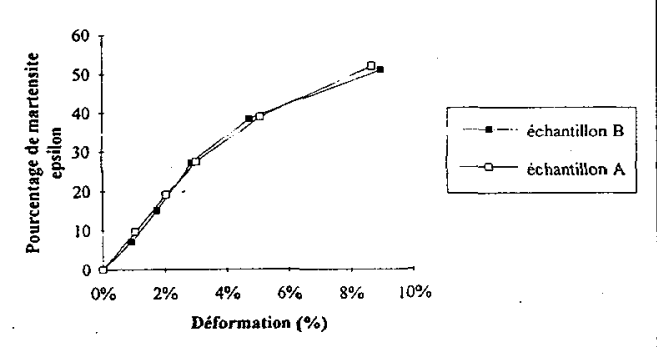

figure 6- Strain induced martensite for restored and recrystallized samples. After Federzoni [9]

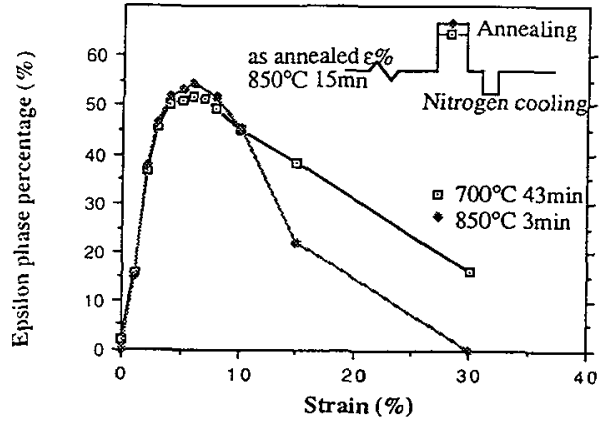

figure 5- Influence of strain before annealing on the thermal $\varepsilon$ martensite fraction. After Federzoni et al [10]

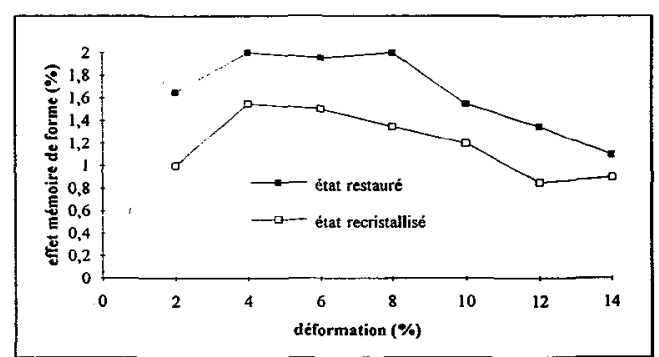

figure 7- Influence of the initial state on the shape memory effect as a function of prestrain. After Federzoni [9]

$\varepsilon$ martensite by strain. However the reversibility, that is to say the SME is influenced as seen on figure 7 : the SME is improved in the restaured sample.

As a conclusion of this, the microstructure has a large influence on the martensitic transformation and the SME. To understand this features some effort have been recently made to precise the geometry of the $\varepsilon$ transformation. 
In spite of its crystallographic simplicity the $\gamma$ to $\varepsilon$ transformation is not so evident from the point of view of involved variants and corresponding homogeneous strains. As well known the f.c.c. to h.c.p. transformation can be accomplished by a/ $6<112>$ faulting on every second $\{111\}$ plane. In a given $\{111\}$ plane the faulting can be performed by 3 different $a / 6<112>$ vectors. An elementary variant can be obtained when the faulting is made by the same vector every second plane. This gives rise to an homogeneous shear of $35.3 \%$ and a shuffling of $2\{111\}$ plane spacing wave length. The number of elementary variants is therefore 4(planes) $\times 3$ (directions) $=12$. Another situation can however be considered : the 3 vectors can act altenatively every second $\{111\}$ plane in such a way that after 3 faults no net homogeneous shear is observed. This "variant" of new kind can be described only in terms of shuffles with 6 \{111\} plane spacing wave length : the transformation does not involve any homogeneous shear, it is no more strictly martensitic. 4 "variants" of this kind are then possible on the $4\{111\}$ planes. The existence of this particular situation has been recently observed in a sample with thermal martensite by high resolution electron microscopy [12]. The single faulting variants have also been observed : the three different variants with the same $\{111\}$ habit plane appears alternately with equal width to insure the self accomodation $[13,14,15]$. However, Yang and Wayman have recently shown that the situation is much more complicated when variants with different $\{111\}$ planes intersect. These authors have shown theoretically and experimentally (TEM) that secondary variants occurs at these intersections $[16,17,18]$. These secondary variants have rotated basal planes and does not correspond to the elementary variants; they are able to perfectly accomodate with the initial variants and to give a self accomodated situation (figure 8). This is claimed by the authors to be very important for the SME process in this kind of alloys. However the reversibility of this situatiion is not so evident and some doubt can be made on this affirmation.

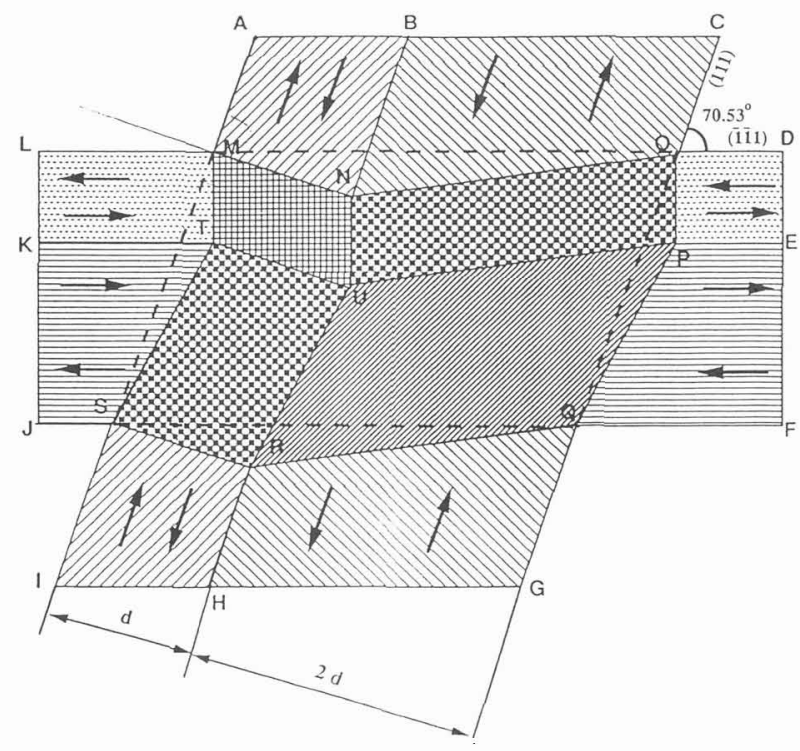

figure 8- Self accomodation configuration of secondary variants at the intersection of two different bands which are self-accomodating elementary variants. The view is done along the [I10] direction which is the conjunction line of the two intersecting (1.11) and (111) planes. After Yang and Wayman [16]

Conclusion concerning the Fe-based alloys :

Some significant progress, experimental as well as theoretical, has been done these last years in the understanding of the $\varepsilon$ martensitic transformation and its consequences on SME properties; however a lot of work must be made on the transformation mechanisms and especially its interaction with the microstructure (grain boundaries, subgrains, dislocations). This is necessary to elucidate for example the new observation of superelasticity. 
The two way memory effect in $\beta$ phase alloys (TWME)

As now well known the TWME corresponds to the spontaneous shape change with temperature between a " high temperature" austenitic shape and a "low temperature" martensitic shape. On cooling during the forward transformation, the shape change is due to the formation of preferential variant(s), on heating the shape recovery is identical to the one observed in the normal one way memory effect. The TWME requires some assymetry in the austenite microstructure provided by some retained oriented martensite or by oriented dislocation arrays [19]. This assymetry is acquired during the so called training processes which involve essentially the thermomechanical cycling. The exact nature of the assymetry and especially its relation with the TWME are still discussed subjects. However, recently a lot of new results have been found, which are able to clarify the situation.

In spite of lack of experimental work, it was generally supposed that, during the cooling, the trained sample is not able to overcome a significant opposed stress, that is to say is not able to provide a work; the results of Stalmans et al $[20,21,22]$ give a clear contradiction to this supposition. The experiments are made on $\mathrm{Cu}-\mathrm{Zn}-\mathrm{Al}$ polycrystalline tensile samples. The training procedure consists of 30 thermal cycles through the martensitic transformation with a contant training traction stress of about $35 \mathrm{MPa}$ followed by 100 pure thermal cycles. This procedure gives a reproducible stable TWME. The trained sample is subsequently subjected to thermal cycles with different constant applied stresses between -52 MPa (compression) and $+70 \mathrm{MPa}$ (traction). The results are drawn on figure 9. It must be precised that in this stress range, the normal TWME is not affected. The striking feature is that the stressed two way memory effect (STWME)
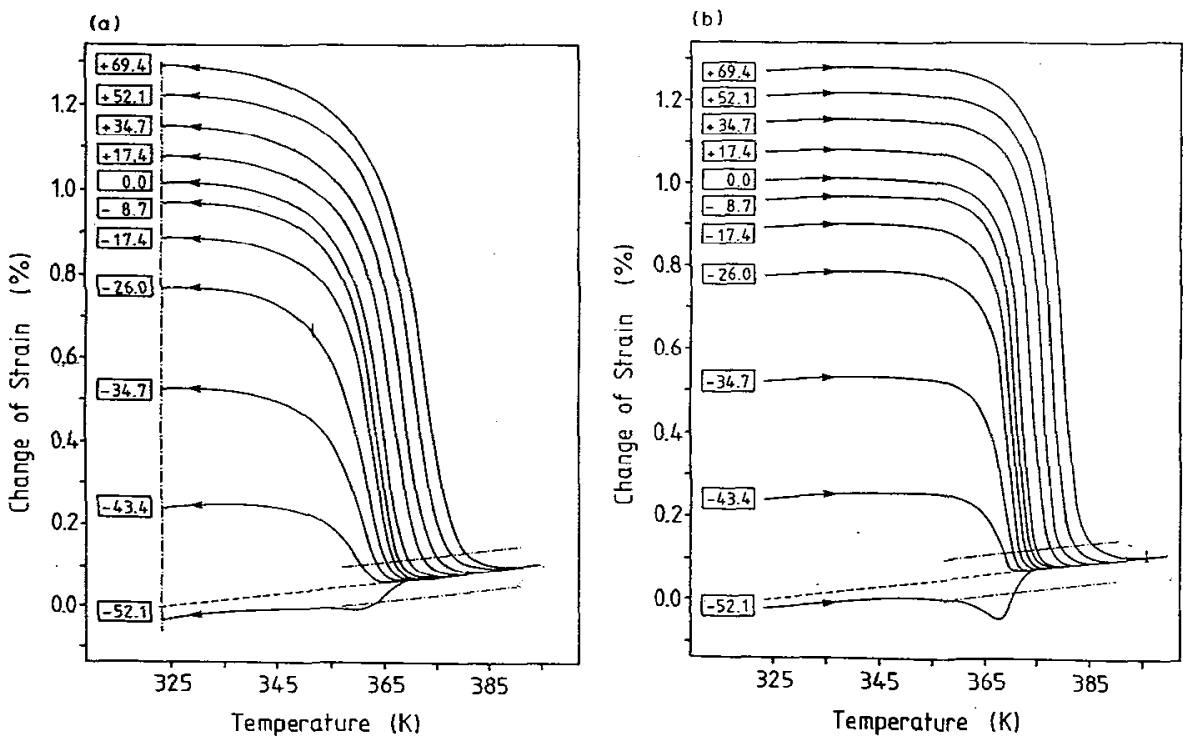

figure 9- Strain-temperature curves during (a) cooling and (b) heating through the transformation region of a trained specimen at different external stresses. The external stresses are indicated in rectangulars in $\mathrm{MPa}$. The pure elastic deformation caused by the loadind has been substracted. After Stalmans et al [20].

indeed exists even in the presence of large opposed stresses which can be precised on figure 10: an opposed stress as high as $50 \mathrm{MPa}$ is necessary to completely suppress the STWME. The STWME therefore can do work since there is a displacement against the opposing force. A maximum work of $0.025 \mathrm{~J} / \mathrm{g}$ is done when the opposing stress is $25 \mathrm{MPa}$; this work is to be compared with a "normal" positive stressing: for the maximum positive stress the work done on heating is 0.115 which is only 4.5 times the maximum work done on cooling. Another interresting fact is that the $\mathbf{M}_{\mathbf{S}}$ temperature is continuously changed by the stress between $+70 \mathrm{Mpa}$ and $-43 \mathrm{MPa}$ with a practically constant slope. This indicates that the same martensite variants are formed at the beginning of the transformation. All these results are well described by a thermodynamical model making the assumption that the training increases the freee energy of the favoured variant(s) less than the one of the other variants; the free energy of the austenite being also increased of an intermediate amount. From the results the free energy difference between the favoured and unfavoured variants is estimated to be $0.24 \mathrm{~J} / \mathrm{g}$. The responsible of the assymetry is clearly due to the presence 
dislocation arrays already described by Rios-Jara et al [23] and Sade et al [24]. This as been recently confirmed by TWME thermal degradation in $\mathrm{Cu}-\mathrm{Al}-\mathrm{Be}$ : the TWME thermal degradation occurs in a temperature range were the dislocations are mobile and rearrrange, this can be seen by in situ TEM [25].

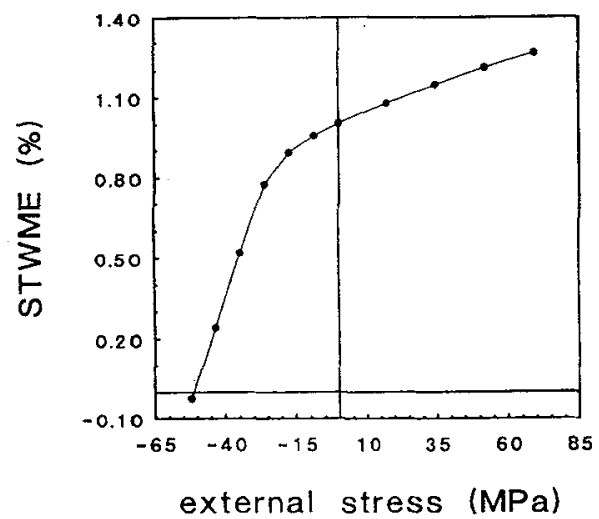

figure 10- The stressed two way memory effect (STWME) as a function of external stress deduced from figure 9. After Stalmans et al [20].

However, the exact mechanism of the action of these dislocation arrays is to be discovered : the idea that the dislocations only favours the nucleation and the very beginning of the growth of the favoured variants [19] is in contradiction with the upper results. The mechanism proposed by Sade et al [26] and Lovey et al [27] takes into account the fact that the Burgers vector of the oriented dislocations is enlarged in some variants (unfavoured) and shortened in others variants (favoured) leading to free energy difference of these variants. This interpretation shoud be qualitatively in good agreement with the upper thermodynamic description, however this mechanism only discriminate 4 variants among 24 and not one (or may be two) as observed, moreover an estimation of the transformation temperature decrease (or increase) shoud be about one order of magnitude smaller in relation to the one corresponding to upper results. The Stalmans' conclusion is that this can be explained by the addition of interaction energy between the dislocations of the complex arrays which is not taken into account in the Lovey's calculation.

Other questions can be made in relation to the TWME mechanism : the Staman experiments, even if made with homogeneous stress are performed on polycrystals where stress (strain) concentration are certainly induced at grain boundaries due to the large strains involved. It is likely that these stress concentrations play an important role. Indeed, it is well known that a single crystal of austenite is much "harder" to train than a polycrystal. For example several thousands of cycles are necessary to obtain a complete TWME [26] for $\mathrm{Cu}-\mathrm{Zn}-\mathrm{Al}$ single crystal trained by pseudoelastic cycling. Very recent results on single crystals are of great interest. In the work of Picornell et al [28] single crystals of $\mathrm{Cu}-\mathrm{Zn}-\mathrm{Al}$ are used with $\mathbf{M}_{\mathbf{S}}$ below room temperature. The training is performed by pseudoelasticity in compression and in tension. The comparison between the two modes is shown on figure $11:$ the streess-strain curves look like different and changes differently with the number of cycles; the TWME, in spite of similar maximum stresses attained during the training, is only present for the compressive mode after 500 cycles. The effect of the stress level during the training is shown in figures 12 and 13. The stress level is adjusted by the temperature of the experiment according to the Clausius-Clapeyron dependance of the critical stress to induce the transformation. The change of the stress-strain curve with the number of cycles is much more pronounced when the stress is high. The subsequent thermal transformation is also modified after high stress : the spreading and the hysteresis of the transformation are increased. The more interesting feature is that the TWME appears only for tension stresses higher than $70 \mathrm{MPa}$ as seen on figure 13. The authors suggest that this threshold is related to the microplasticity of the martensite which occurs above this value whereas the macroscopic plastic deformation is not attained. The microplasticity is associated with the formation of dislocation arrays which also modify the spreading and the hysteresis of the transformation. As already described elsewhere $[25,26]$ the dislocations are generally with Burgers vector $b=\langle 100\rangle$ and line direction $\mathrm{u}=<111>$ in the $\beta$ phase which correspond in the favoured martensite variant to the slip in the basal plane. Some TWME with opposing stress are also made in this study (figure 14): the single crystal is also able to give work on cooling. The big difference with the case of polycrystal [20] is that the stress level is much smaller and needs a much larger number of cycles. 


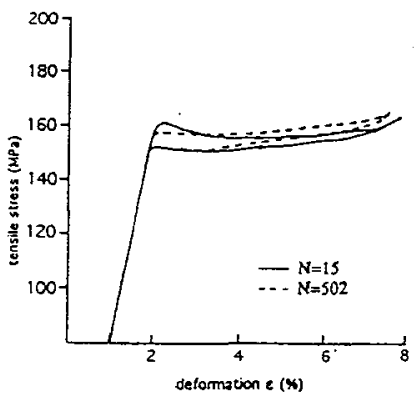

a
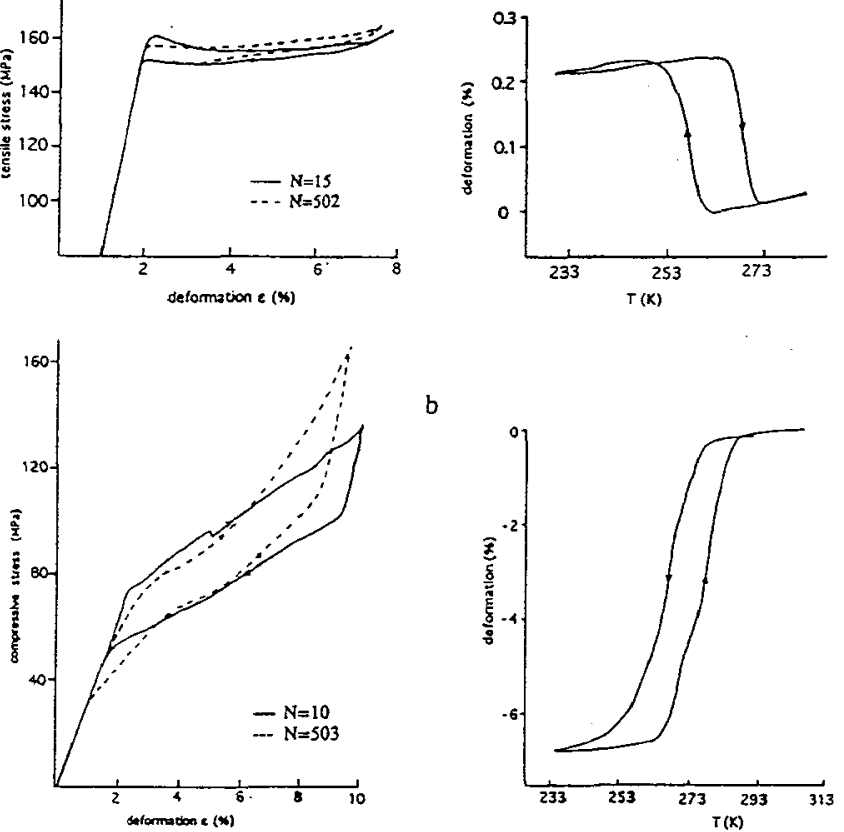

figure 11- Stress-strain and dilatometric curves obtained after 500 pseudoelastic cycles (a) cycling in tensile mode and (b) cycling in the compression mode. After Picornell et al [28]

Another interesting new result related to this aspect is given by Pons et al [29]. This one is concerned with the pseudoelastic tensile cycling and the resulting TWME in single crystals of $\mathrm{Cu}-\mathrm{Zn}-\mathrm{Al}$ with and without small $\gamma$ precipitates. The samples are thermally treated to contain small coherent $\gamma$ precipitates of about $10 \mathrm{~nm}$ mean size and average spacing of 100-200 nm. The evolution of stress-strain pseudoelastic loops with the number of cycles is shown on figure $15:$ a clear decrease of the critical stress necessary to induce the martensite is seen whereas the stress at the end ofthe transformation is not significantly lowered. This is in clear contrast with results related to precipitate free samples (see figure 11 [28]) : in tension the stress-strain loop is little affected with only a slight stress increase at the end of transformation in compression the critical stress is also lowered but less than in the present case and a significant "hardening"is observed to complete the transformation. As shown for precipitate free samples, the cycling induces dislocation arrays; the striking point is that the amount of these defects after the same number of cycles is much lower in the case of samples with precipitates. A study of the precipitates by electron microscopy shows that these ones after the pseudoelastic cycling are encircled by some contrast which can be interpreted as due to dislocation loops with $\langle 100\rangle$ Burgers vector. A mechanism has been proposed by Lovey at al [30] to explain the formation of the dislocations around the precipitates.Concerning the TWME, the interesting fact is that in identical conditions of stress, the $\gamma$ precipitates samples "takes" the TWME with a number of cycles which is about one order of magnitude lower than the one corresponding to the precipitate free samples. It is therefore clear that the precipitate+dislocations groups are responsible for the TWME. The interaction mechanism of these complex defects with the favoured variant is not precised by the authors. It can be thought that the precipitate+dislocations defects create some internal stress in the same direction of the one which induces the favoured variant. This internal stress is not homogeneous but is however well distributed inside the material (well dispersion of precipitates) and statistically it should reduce the critical stress to induce the favoured variant (figure 15). On cooling this internal stress induces the favoured variant. Some opposing stress TWME experiments are also done in this work which give opposed stresses to reduce the TWME by 

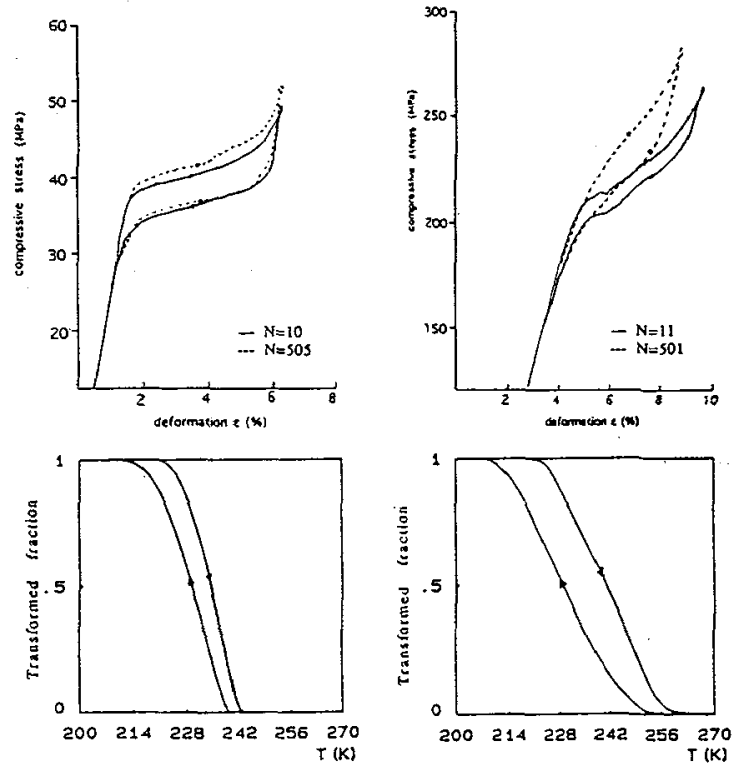

figure 12- Changes in the pseudoelastic curves for two different applied stress values and the corresponding thermal cycles after training.

After Picornell et al [28]

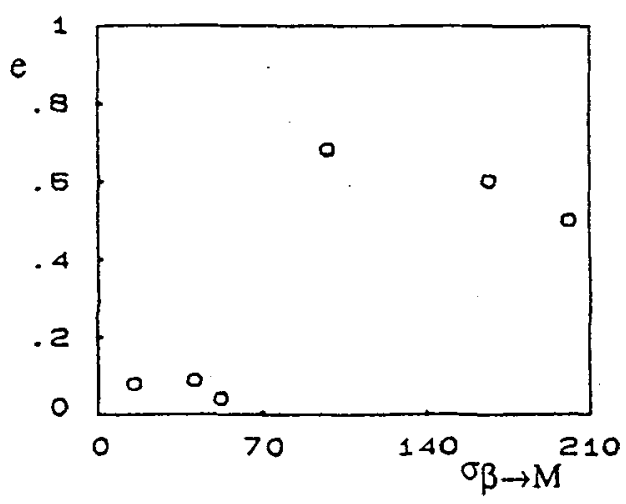

figure 13-Efficiency of TWME after 500 pseudoelastic cycles as a function of the stresss level.

After Picomell et al [28]

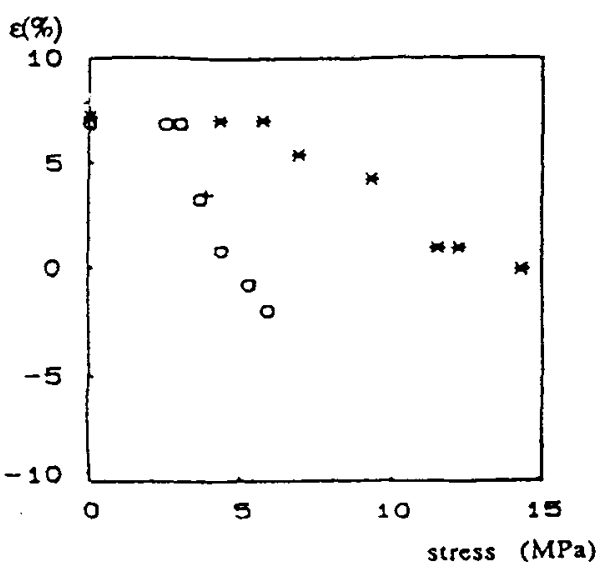

figure 14- Deformation on cooling as a function of opposed tensile stress for +4200 cycles at $110 \mathrm{MPa}$ o 16000 cycles at $120 \mathrm{MPa}$

$50 \%$ of about 3-4 MPa. This is consistent with the fact that the stress at $50 \%$ transformation in the stressstrain curves is reduced by the training of approximately $15 \mathrm{MPa}$.

From all of these recent results, I should presently conclude that the TWME mechanism is generally related to well distributed oriented stress centers. In the last upper case these stress centers are clearly identified as the modified precipitates. In the case of precipitate free single crystals (Lovey et al present conference) these centers could be the complex dislocation defects. In the case of polycrystals the relative facility to obtain a good TWME (with possibility of large opposing stresses) should be due to the stress (strain) concentration which occurs at grain boundaries. The most powerfull stress centers (dislocation arrays) are therefore probably concentrated close to the grain boundaries. If the stress center distribution is sufficiently homogeneous this description should not be opposed to the thermodynamic treatment given by Stalmans. 
figure 15- Stress-strain curves obtained at different stages of cycling for a sample containing small precipitates. After Pons et al [29]

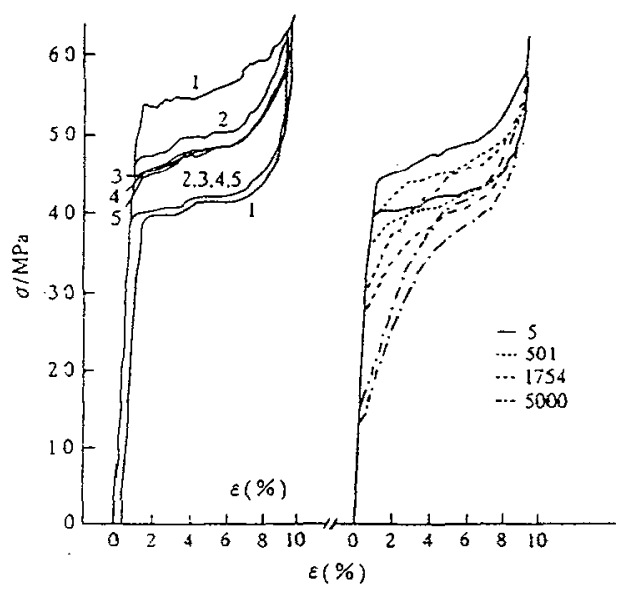

References

[1] Maki T.,Materials Science Forum 56-58 (1990)157-168

[2] Sato A., Chishima E., Soma K. and Mori T.,Acta Metall. 30 (1982) 1177-1183

[3] Sato A., Soma K., Chishima E. and Mori T., "Int. Conf. Mart. Transf. 82", Leuven 8-12 august 1982 (Les Editions de Physique, 1982) pp.797-802

[4] Sato A., Yamaji Y. and Mori T., Acta Metall., 34 (1986) 287-294

[5] Murakami M., Otsuka H., Suzuki H.G. and Matsuda S., "Int. Conf. Mart. Transf. 86", Nara 26-30 august 1986 ( The Japan Institute of Metals , 1987) pp. 985-90

[6] Yang J.H., Chen H. and Wayman C.M., Metall. Trans. 23A (1992) 1431-1437

[7] Yang J.H., Chen H. and Wayman C.M., Metall. Trans. 23A (1992) 1439-1444

[8] Yang J.H. and Wayman C.M., Metall. Trans. 23 A (1992) 1445-1454

[9] Federzoni L. Thesis, INSA Lyon, 1993

[10] Federzoni L., Gex D., Gu Q., Guenin G., Labrosse D., Mantel M. and Van Humbeeck J., "Int. Conf. Mart. Transf. 92", Monterey 20-24 july 92 (Monterey institute of advanced studies, 1993) pp.1175-1180 [11] Otsuka H.,Kajiwara S. and Ishihara T.,"Int. Conf. Mart. Transf. 92", Monterey 20-24 july 92 (Monterey institute of advanced studies, 1993) pp. 1169-1174

[12] Putaux J.L., Federzoni L., Mantel M., Blanc G. and Chevalier J.P., "EUROMAT 93",( to be published in Journal de physique, 1994)

[13] Maki T. and Tsuzaki K., "Int. Conf. Mart. Transf. 92", Monterey 20-24 july 92 (Monterey institute of advanced studies, 1993) pp. 1151-1162

[14] Yang J.H. and Wayman C.M., Materials Characterization 28 (1992) 23-35

[15] Yang J.H. and Wayman C.M., "Int. Conf. Mart. Transf. 92", Monterey 20-24 july 92 (Monterey institute of advanced studies, 1993) 1193-1198

[16] Yang J.H. and Wayman C.M., Materials Characterization 28 (1992) 37-47

[17] Yang J.H. and Wayman C.M., Acta metall. mater. 40 (1992) 2011-2023

[18] Yang J.H. and Wayman C.M., Acta metall. mater. 40 (1992) 2025-2031

[19] Guénin G., Eur. Conf. " The martensitic transformation in science and technology", Bochum 9-10 march 1989 (DGM informationsgesellschaft . verlag, 1989) pp.39-52

[20] Stalmans R., Van Humbeeck and Delaey L.,Acta metall. mater. 40, (1992) 2921-2931

[21] Stalmans R., Van Humbeeck and Delaey L., Materials trans. JIM 33 (1992) 289-293

[22] Stalmans R., Van Humbeeck and Delaey L., "Eur. symp. on martensitic transf. and shape memory properties", Aussois 16-78 sept.1991 (Journal de Phys. supl. C4, 1991) pp. 403-408

[23] Rios-Jara D. and Guénin G., Acta metall. 35 (1987) 109-119

[24] Sade M., Uribarri A. and Lovet F.C., Phil. Mag A55 (1987) 455

[25] Flores-Zuniga H., Rios-Jara D. and G. Guénin, to be published

[26] Sade M., Hazarabedian A. Uribarri A. and Lovey F.C., "Int. Conf. on Phase Transf. ", Cambridge

1987 (ed. Lorimer, 1987) p.279

[27] Lovey F.C., Hazarabedian A. and Garces J.E., Acta metall. 37 (1989) 2321-2327

[28] Picornell C., Sade M. and Cesari E., Metall. and mater. trans. 35 A (1994) in press

[29] Pons J., Sade M., Lovey F.C. and Cesari E., Mater. trans. JIM 34 (1993) 888-894

[30] Lovey F.C., Torra V., Isague A., Roqueta D. and Sade M., Acta metall. and mater. 42 (1994) 453460 